\title{
Strategy in Suriname How do organizations in Suriname Strategize?
}

\author{
Dr. Miguel Goede \\ Anton de Kom, University of Suriname \\ Roy Laurens \\ Anton de Kom, University of Suriname \\ Robert Gilaard \\ Anton de Kom, University of Suriname \\ Robby Rijssel \\ Anton de Kom, University of Suriname \\ Delano Gefferie \\ Anton de Kom, University of Suriname
}

\begin{abstract}
Purpose - There are few textbooks available on strategic management based on nonWestern practices. This might be a consequence of the lack of studies on strategic management in these countries. The purpose of this article is to describe how organizations in Suriname strategize. Methodology - For this study a brief literature review was conducted, a survey was held and the results were discussed with faculty and students of Anton de Kom, University of Suriname. Findings - Organizations in Suriname do strategize. The economy is the most important factor organizations take into account. The factor that is taken least into account is the ecology. Other factors that are important are social. The multicultural society is taken into account. The political factors, surprisingly, score relatively low. Originality - The paper contributes to the understanding of strategizing by Suriname's organization and other Caribbean Small Island Developing States (SIDS). Conclusions - Organizations in Suriname do strategize. The economy is the most important factor organizations take into account. The factor that is taken least into account is the ecology.
\end{abstract}

Key words: Suriname, SIDS, Strategy, PESTLE, Competitive Advantage Business-level strategies

\section{INTRODUCTION}

Suriname is a Small Island Development State (SIDS) that obtained its independence from the Netherlands in 1975 . Its territory is 165,000 square kilometers, and the population is 560,000 . It is part of the smallest country in South America and is located on the North coast. Suriname is the only Dutch speaking member of the Caribbean Community (CARICOM), since 1995.

Suriname has a market economy and has not performed too well economically the last couple of years, despite the fact that this multicultural country might be one of the richest countries in the world based on the availability of natural resources (Schmeitz, 2018). Suriname began as an agricultural economy and became an economy dominated by mining, mainly bauxite (starting around 1916), and now also gold and from the 1980s oil (Hout, 2014). Suriname has a 
large informal economy, estimated between 35\% and 45\% (Peters, 2017) and a sizeable public sector. Its infrastructure has improved through the years. There is no robust private sector. ... Suriname failed to develop a robust private sector. The economy has produced no large private-sector companies, and of those small- and medium-sized businesses that do exist, many are limited to selling goods and services to the government and importing products for the general population not produced locally. When government finances were cut over the past two years, the pain quickly rippled into the private sector. The combination of these factors resulted in a state-dominated economy that was unable to respond quickly to changing market conditions. (MacDonald, 2018)

The relative importance of agriculture in Suriname's economy has declined over the last two decades. Meanwhile, as agricultural output fluctuated, the country's economic growth was boosted by development in the mining and services sectors. However, agriculture is still socio-economically significant, as it is a major provider of employment in rural areas, accounts for 5\% of the country's foreign exchange earnings, and is a key contributor to food security through the production of rice, the population's main staple food. (Derlagen, Tas, Boyce, Shik, \& De Salvo, 2017)

The economy is highly dependent on the export of commodities. The gains of the boom (20012014) are gone. The country is going through a recession (MacDonald, 2018). ${ }^{1}$

Suriname's economy is dominated by the mining industry, with exports of oil and gold accounting for approximately $85 \%$ of exports and $27 \%$ of government revenues. This makes the economy highly vulnerable to mineral price volatility. ${ }^{2}$

Students are taught business and management at the university level using Western books, mainly American publications. This is, among other factors, a result of a lack of local research and literature. There is some research, however: A study from 1995 describes how small and medium agriculture and handicraft enterprises cope (Roseval, 1995). That is why we researched how Surinamese organizations consider and implement strategy.

For the purpose of this study we define strategy as the direction and scope of an organization for the long-term, which achieves advantage for the organization through its configuration of resources within a challenging environment, to meet the needs of markets and to fulfill stakeholders' expectations. In other words, strategy is about:

- Direction: Where is the business aiming to get to in the long-term?

- Markets: Which markets should an organization compete in and what kinds of activities take place in such markets?

- Advantage: How can the organization perform better than the competition in those markets?

- Resources: What resources (skills, assets, finance, relationships, technical competence and facilities) are required in order to be able to compete?

- Environment: What external factors affect the business's ability to compete?

- Stakeholders: What are the values and expectations of those who have power in and around the business? (What is strategy, 2018)

1 Suriname Economy Profile 2018. (2018). Indexmundi.com. Retrieved 1 June 2018, from

https://www.indexmundi.com/suriname/economy_profile.html

2 https://www.indexmundi.com/suriname/economy_overview.html 


\section{METHODOLOGY}

The authors have followed a data triangulation strategy to seek data validation based on the cross-verification of the analyzed data sources. For this study, a literature review was conducted. Descriptive statistics were applied. A questionnaire was developed and distributed. In this article we looked into the different factors that influence organizations in Suriname when developing their organization strategies.

One hundred seventy managers and directors from 170 diverse organizations participated in a convenience sample. There was no limitation by size, age or the sector the organization operates in to participate in the survey. The only criteria were that the business has to be fully operational in Suriname and that the respondents had to have a managerial or executive position in which they contribute to shaping the strategy of their organization. The survey was conducted in March 2018. The survey was based on the following variables: age of the organization, size, sector in which the organization operates, if the organization has a mission and a vision statement, if there is a strategic plan, how far ahead the organization plans, if the strategy is internationally oriented, the importance of the PESTLE factors (Political, Economic, Sociological, Technological, Legal, and Environmental), and the strategy of the organization.

This article answers the following questions about how organizations in Suriname strategize:

1. Does size of the organization determine whether or not strategic planning is used by management?

2. Does the age of the organization influence the strategy?

3. Does the category of the organization determine if strategic planning is used by management?

4. To what extent do macro environmental factors influence the strategy of a business?

5. How many organizations per category are applying Competitive Advantage Businesslevel strategy options?

\section{LITERATURE REVIEW}

Strategy is an expression of how an organization needs to adapt over time to meet its aims, after a thorough assessment of the external environment. Developing an organizational strategy for an organization involves first comparing its present state to its desired state to establish the differences and then stating what is required for the desired changes to take place (Porter, 2018).

The strategy of an organization is dynamic and is for the longer term. The influence of external (risk) factors on the strategy varies per sector, age and size of the organization.

When an organization has identified both internal and external influences, it must respond quickly to them and make necessary changes in its strategy to remain competitive. This analysis also provides the opportunity to discover trends.

The field of strategy looks like a jungle to many people. Mintzberg et al. (1998) went on a safari and mapped this jungle. They stated that there are at least ten schools.

\section{School of design}

Views strategy development as a process of realization, achieving a fit between the organization's internal abilities and external possibilities. The SWOT Analysis is often used here. 


\section{School of planning}

Praises the advantages of formal strategic planning to a great extent and arms itself with formal procedures, training, analysis and lots of numbers. Inspired by Igor Ansoff among others.

\section{School of positioning}

This school is heavily influenced by Michael Porter's assertion that strategy is dependent on the way the company is positioned in the market and the industry. Typically views strategy development as an analytical process, where you have to choose the right strategy among a limited amount of generic types.

\section{School of entrepreneurship}

Emphasizes the manager or leader's central role as the one who creates the strategy and carries the vision. This means that the strategy is flexible and can be adapted to the leader's experiences.

\section{The cognitive school}

Examines what happens in the mind of the strategist and sees strategy as a mental process, where there is room for creative interpretations. Strategists, of course, have different cognitive styles, for instance extrovert or introvert, thinking or feeling.

\section{School of learning}

Views strategy as an emergent process. This means that strategies occur as people gain more knowledge of a situation and of the organization's ability to handle it. This way, the formulation and implementation are intertwined.

\section{School of power}

Considers strategy a result of different power plays both inside and outside the organization. Negotiation is a central element of the power school.

\section{School of culture}

Strategy creation is viewed as a process that is rooted in the social power of the culture. It focuses on common interests and integration.

\section{School of surroundings}

Focuses on the powers that surround the organization. A company's strategy depends on events occurring in the surroundings and the organization's reaction to them.

\section{School of configuration}

Views strategy as a process that transforms the organization. This school describes a strategy's relative stability that is interrupted by occasional dramatic leaps to new stages. ${ }^{3}$

PESTLE is an acronym for a method used to identify the macro (external) forces influencing an organization. The letters stand for Political, Economic, Social, Technological, Ecology (Environmental) and Legal (Oxford, 2018). In the following paragraphs these factors are discussed further.

\footnotetext{
${ }^{3}$ https://lederindsigt.dk/en/tools-templates/strategy-business-development/henry-mintzberg-s-10-schools-ofstrategy
} 
Political factors. When analyzing the political factors, we are analyzing the way in which politics impacts an organization's strategy. Some of the ways in which politics influences an organization are: stability of the government, government policy and elections, level of corruption, especially the ruling parties, trends in the regulations. It concerns all political actions at administrative, district, regional and international levels (Contributor, 2018). The political factors can influence the other factors in the PESTLE analysis because lawmakers can create laws on all these factors. Therefore, it is almost impossible to consider political factors without including the other factors of the PESTLE in the decision making (Yüksel, 2012).

Economic factors. Economic factors include interest rates, inflation figures, economic growth forecasts, unemployment level, labor costs, productivity and fiscal policies. Economic factors have an influence on entrepreneurial activity (Castaño, Méndez, \& Galindo, 2015).

Socio-cultural factors. The impact of socio-cultural factors on an organization's strategy is an understudied field (Thornton, 2011). Thornton and colleagues' research on the relationship between entrepreneurial activity and socio-cultural factors proves that socio-cultural factors could influence decisions when creating new businesses. Castaño's (2015) study on the effect of social, cultural, and economic factors on entrepreneurship indicates the following: Adequate social structures foster entrepreneurship. Summarizing, in countries where the rule of law is more advanced and individuals have high economic freedom, extensive entrepreneurial activity is more common. Societies with less corruption and better training and education have higher levels of entrepreneurial activity (Yüksel, 2012).

Technological factors. Technology has become a vital part of every organization today, as most of the operations are Internet-based and technology-driven. Therefore the importance of the technology environment is critical (Bughin et al., 2011).

There are two types of technological change: there are developments in ICT and there are developments in technology specific to an industry or market, for example enhancements to manufacturing technology. ICT developments can instigate profound business impacts, often across industries or business domains and on a series of organizations. These are the so-called distributive technologies. It is often the case that there is a failure to recognize the potential use of the technology - at least until a competitor emerges with a new or enhanced offering. For example, increased functionality of mobile technology or extended bandwidth for Internet transactions can present opportunities to many organizations (Cadle, Paul, \& Turner, 2010). Other disruptive technologies are blockchain, robotics and nano technology. 4

Legal factors. Legal factors are external factors which refer to how legislation affects the way businesses operate and customers behave. Legal factors are the factors that affect businesses as a consequence of government regulations. They play a big part in regulating how organizations operate, what taxes they pay and what profits they receive, as well as how customers behave. Examples include the laws regulating importation and exportation. There is always an interrelationship between legal, political and economic factors (Yüksel, 2012).

Ecological or environmental factors. Environmental factors include infrastructure, cyclical weather, disposal of materials, energy availability and cost, and the ecological consequences of

${ }^{4}$ These 5 disruptive technologies are driving the circular economy. (2018). World Economic Forum. Retrieved 16 May 2018, from https://www.weforum.org/agenda/2017/09/new-tech-sustainable-circular-economy/ 
production processes. In Suriname, there is the environmental law and the "Nationaal Instituut voor Milieu en Ontwikkeling in Suriname" (NIMOS) that has set terms which organizations in different sectors must comply with.

\section{THE MODEL OF GENERIC STRATEGIES FOR COMPETITIVE ADVANTAGE BUSINESS-LEVEL STRATEGIES}

Using a PESTLE analysis in order to analyze external factors is one of the first steps when strategizing. Analyzing the potential impact on the organization is the next step. It is important that the results are constantly tested and adapted to the actual situation of organization.

Porter introduced the Model of Generic Strategies for Competitive Advantage Business-level strategies. According to Porter an organization's core competencies should be focused on satisfying customer needs or preferences in order to achieve above average returns. This is done through Business-level strategies. Business-level strategy is all about an organizations' position in an industry compared to competitors and to the five forces of competition (Supplier power, Buyer power, Competitive rivalry, Threat of substitution, Threat of new entry). There are four business strategies: Cost Leadership, Differentiation, Cost Focus and Differentiation Focus.

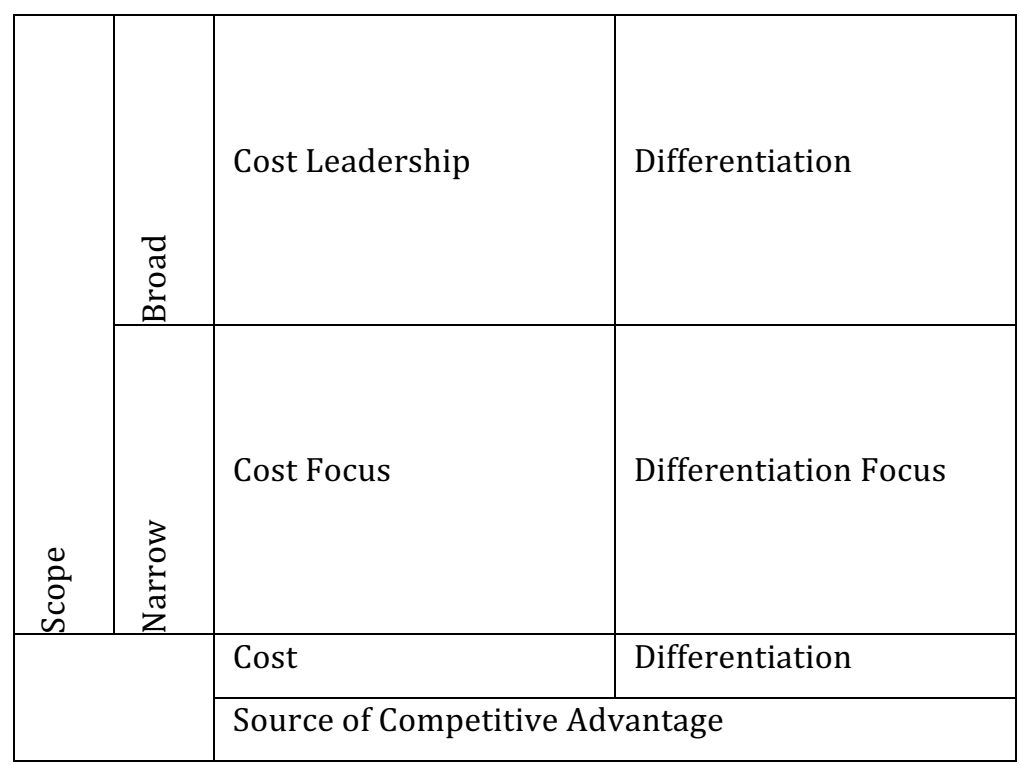

Figure 1: The Model of Generic Strategies for Competitive Advantage Business-level strategies

\section{Cost Leadership}

The objective is to become the lowest-cost producer in the industry.

The classic method to achieve this objective is to produce on a large scale, which enables the business to exploit economies of scale.

Why is cost leadership potentially so important? Many market segments in the industry are supplied with the emphasis placed on minimizing costs. If the achieved selling price can at least equal (or near) the average for the market, then the lowest-cost producer will enjoy the best profits.

This strategy is usually associated with large-scale businesses offering standard products with relatively little differentiation that are readily acceptable to the majority of customers. Occasionally, a low-cost leader will also discount its product to maximize sales, particularly if it 
has a significant cost advantage over the competition and, in doing so, it can further increase its market share.

A strategy of cost leadership requires close cooperation between all the functional areas of a business. To be the lowest-cost producer, a firm is likely to achieve or use several of the following strategies:

- High levels of productivity

- High capacity utilization

- Use of bargaining power to negotiate the lowest prices for production inputs

- Lean production methods (e.g., JIT)

- Effective use of technology in the production process

- Access to the most effective distribution channels

\section{Differentiation Leadership}

With differentiation leadership, the organization targets much larger markets and aims to achieve competitive advantage through differentiation across the whole of an industry.

This strategy involves selecting one or more criteria used by buyers in a market and then positioning the business uniquely to meet those criteria. This strategy is usually associated with charging a premium price for the product or service, often to reflect the higher production costs and extra value-added features provided for the consumer.

Differentiation is about charging a premium price that more than covers the additional production costs and giving customers clear reasons to prefer the product over other, less differentiated products.

This is achieved in several ways:

- Superior product quality (features, benefits, durability, reliability)

- Branding (strong customer recognition and desire, brand loyalty)

- Industry-wide distribution across all major channels (i.e., the product or brand is an essential item to be stocked by retailers)

- Consistent promotional support - often dominated by advertising, sponsorship, etc.

Good examples of a differentiation leadership include global brands like Apple and Mercedes. These brands achieve significant economies of scale, but they do not rely on a cost leadership strategy to compete. Their business and brands are built on persuading customers to become brand loyal and paying a premium for their products.

\section{Cost Focus}

With cost focus an organization seeks a lower-cost advantage in just one or a small number of market segments. The product is basic or simple and perhaps similar to the higher-priced product offered by the market leader, but acceptable to sufficient consumers.

\section{Differentiation Focus}

This is the niche marketing strategy. In the differentiation focus strategy, an organization aims to differentiate within just one or a small number of target market segments. The special customer needs of the segment mean that there are opportunities to provide products that are clearly different from those of competitors who may be targeting a broader group of customers. 
The important issue for any business applying this strategy is to ensure that customers really do have different needs and wants-in other words that there is a valid basis for differentiation-and that existing competitor products are not meeting those needs and wants.

Many small organizations are able to establish themselves in a niche market segment using this strategy, achieving higher prices than un-differentiated products through specialist expertise or other ways to add value for customers.

\section{Caught in the middle strategy}

Some firms fail to effectively pursue one of the generic strategies. A firm is said to be stuck in the middle if it does not offer features that are unique enough to convince customers to buy its offerings, and its prices are too high to compete effectively based on price.

\section{RESULTS}

How do organizations in Suriname actually plan? Between the $5^{\text {th }}$ and the $18^{\text {th }}$ of March 2018, 170 organizations participated in the survey.

Some $17.4 \%$ of the organizations are younger than five years, $17.4 \%$ are between 6 and 10 years, $19.8 \%$ are between 11 and 20 years, and $45.5 \%$ are older than 21 years. Organizations older than 21 years are most represented in this survey. The second most represented organizations are the organizations between 11 and 20 years. The younger organizations, both younger than five years and between six and 10 years, are almost evenly represented in this survey. The total of all organizations is $100 \%$.

Some $23.2 \%$ of the organizations are large ( $>250$ employees), $17.3 \%$ are middle $(<250$ employees), $25.00 \%$ are small ( $<50$ employees), and $34.5 \%$ are micro ( $<10$ employees).

The organizations operate in the sectors indicated in Table 1.

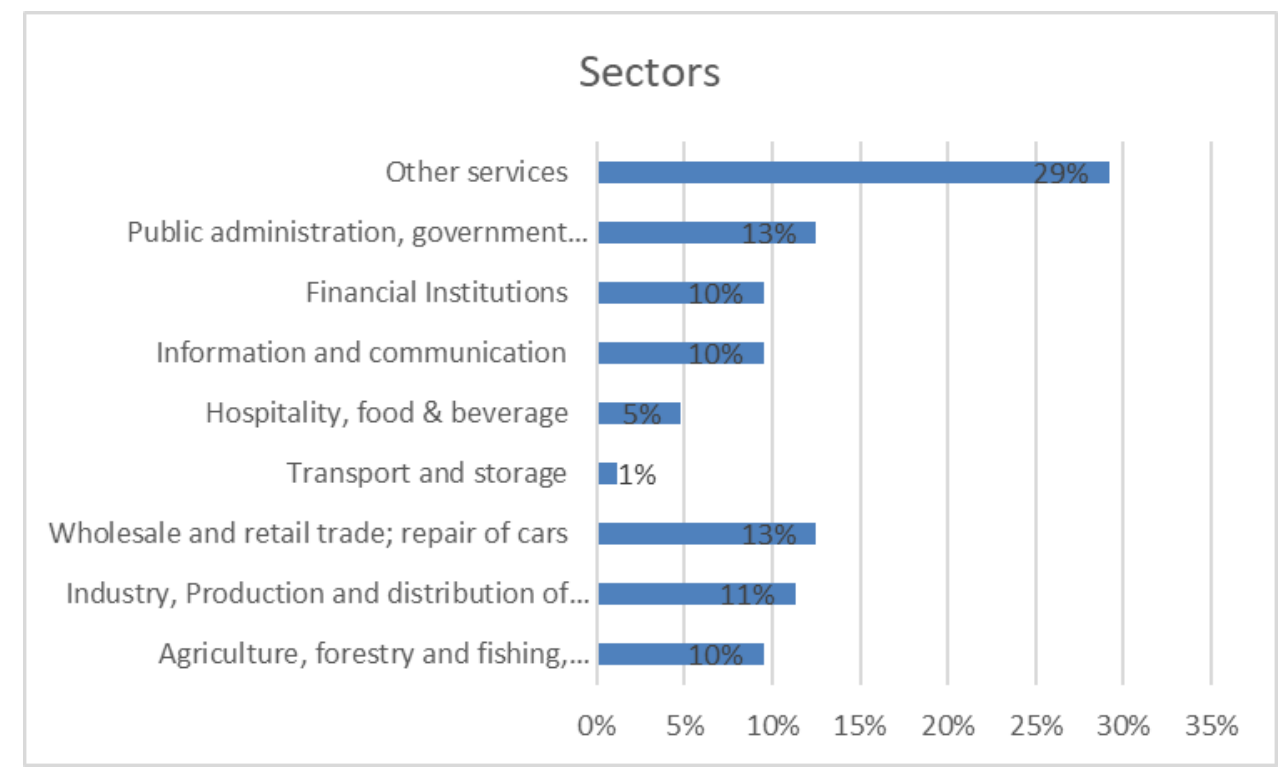

Figure 2: Sectors of organizations

Although this is a convenience sample, the relatively big size of sectors is no coincidence: Big public sector, big industry and agriculture sector. There is no clear explanation why $29 \%$ indicated operating in sector "Other services". 


\section{MISSION AND VISION STATEMENT}

Eighty-five percent of the surveyed organizations have a mission and vision statement. The sector with most organizations with a mission and vision statement is the sector "Other services" with 29\%, followed by sector "Public Administration etc." with 12.5\%. The third place goes to sector "Information and communication" with $9.5 \%$ having a mission and vision statement.

Some $45.5 \%$ of organizations are older than 21 years and $88.2 \%$ of these organizations have a mission and vision statement.

\section{Strategic plan}

Some $85.8 \%$ have a strategic plan of which $63.9 \%$ is a written strategic plan. Some $43 \%$ of the organizations that have a written strategic plan have prepared it for five years. Most of the big organizations (92\%) and middle organizations (91\%) in Suriname have a written strategic plan, while only $61 \%$ of the small organizations and $36 \%$ of the micro organizations write their strategy down.

Organizations older than 21 years have a written strategic plan (75\%), followed by organizations between 11 and 20 years (69\%). It is noticeable that the percentage for organizations between 6 and 10 years and younger than 5 years who don't have a written strategic plan is relatively high.

The category "Other Services" has the highest score for having a (written) strategic plan (21\%). Sector "Public Administration ..." is the second sector (12\%). 79\% of the strategic plans in this sector are written. The sectors with the least representation with regard to written strategic plans are sector "Wholesale" (4\%), followed by sector "Hospitality" (2\%) and sector "Information and Communication" (1\%).

\section{Planning}

Seventy percent of the organizations plan ahead. Thirty percent do not plan; 55.4\% plan five years ahead, $9 \%$ plan 10 years ahead, and $4.8 \%$ plan 20 or more years ahead.

\section{Internationally oriented}

Another question during the survey was related to whether the organization is internationally oriented or not. Seventy-three percent of organizations have stated that their strategy is international oriented. Of the organizations that have a strategy that is internationally oriented, $27 \%$ are big organizations and $26 \%$ are small organizations.

\section{PESTLE}

Different factors influence the organizations' strategies. In this section the factors that influence the strategy are discussed. The factors which are discussed are politics, economy, technology, legal and ecology (PESTLE). 


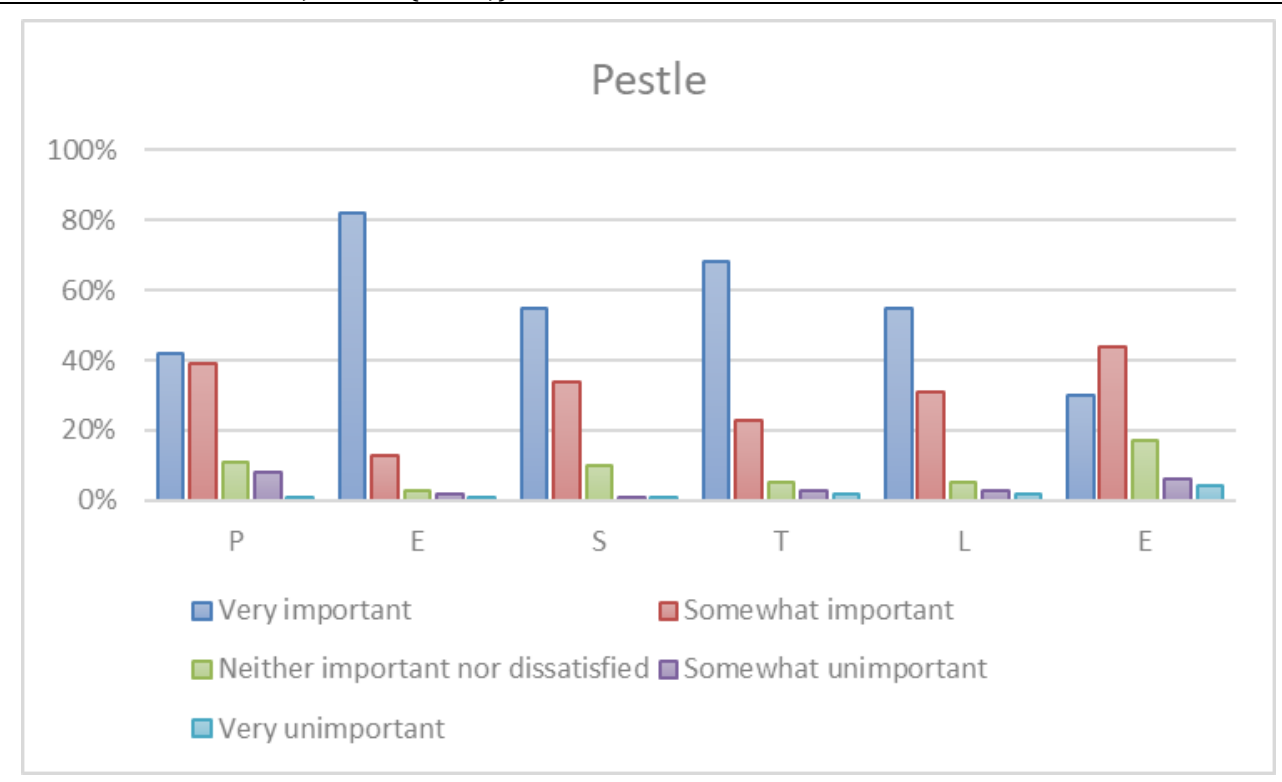

Figure 3: How important are the PESTLE factors?

Eighty-two percent of the surveyed organizations consider that the economy has significant influence on its strategy. Sixty-eight percent of the organizations consider the influence of technology significant technology, followed by the social factors (55\%) and legal factors (55\%). Respectively, $42 \%$ and $30 \%$ of the surveyed organizations find political and ecological factor very important to their strategy.

It is noticeable that the economy is the most important factor when crafting the strategy in Surname. It is also noticeable that the factor ecology is the least important, given the fact that the environment is essential for the survival of humankind.

\section{Political}

Most organizations, regardless of age, think that the political factor in Suriname is very important to fairly important $(80.4 \%, 41.7 \%$ plus $38.7 \%)$. Only two organizations do not think it is important.

Regardless of the size of the organization, politics is considered important in formulating strategy. Most organizations between 0 and 10 years find the political factor in strategy somewhat important in comparison with organizations older than 10 years. Organizations over 10 years find political factor in strategy formulation very important.

As an organization ages, they realize that political factors play a very important role in strategy formulation. In a small country such as Suriname it is understandable that politics exert relatively a large influence on organizations.

\section{Economics}

Eighty-two percent of the surveyed organizations find that the economy has a very important influence on their strategy. This is by far the most important factor to consider when strategizing in Suriname.

\section{Social}

Fifty-five percent of organizations assume that social factors are very important in strategy formulation in Suriname. Regardless of size, age and category or sector, almost every organization takes social factors into account in its strategy formulation. The assumption is that social factors play such a big role in Surinamese organizations because Suriname has a 
diverse culture, which cannot be ignored. Every culture is different, so organizations must take this into account in their strategy formulation. Apart from that, there are other general social factors that must be taken into account, such as the spending pattern of consumers that looks different now in the bad economic situation; most people in families have more than one job, etc.

\section{Technology}

Most organizations (68\%) find the technological factor very important in strategy formulation in Surinamese organizations. This is important in all age categories, regardless of the size of the organization. Technology is an important factor that is taken into account. Most organizations are aware that keeping up with technology has an impact on their competitiveness, effectiveness and efficiency. It also contributes to the innovation of the business processes and the development of new products and services and business models. In most organizations in Suriname it is noticeable that adaptation of innovation, especially in the area of social media, is constantly increasing. This factor plays an important role in determining which type of business level strategy an organization will apply.

\section{Legal}

Most organizations (55\%) find legal framework in their strategy very important. The legal factors become more important as the organization gets older and bigger. It is necessary that organizations grow more aware of the laws and regulations that are in place in Suriname. Also, when they are entering into foreign markets, regulations are important to take into account.

\section{Ecology or environmental}

Only $26.6 \%$ find the ecological factors very important in formulating their strategy. Some $43.8 \%$ find the ecological factors somewhat important in strategy formulation. Organizations are not yet aware enough of their corporate responsibility concerning the environment; they do not yet see the long-term consequences of neglecting these factors. There is not enough pressure from the civil society on the organizations to take these factors into consideration when strategizing. It is noteworthy that there are exceptions; some organizations are already using green strategies.

There is no relation between the age of an organization and taking the ecology factor into account when establishing a strategy. We did not expect this outcome; we thought that the organizations younger than ten years established a plan for protection of the environment.

\section{COMPETITIVE ADVANTAGE BUSINESS-LEVEL STRATEGIES}

While strategy is important to organizations, these strategies could be presented in various options.

Most of the organizations apply differentiation leadership (33\%) as a strategy option, followed by cost leadership (28\%). Twenty-one percent of the surveyed organizations use differentiation focus as an option and fewer of the organizations use cost focus $(7 \%)$ or other strategies $(11 \%)$. 


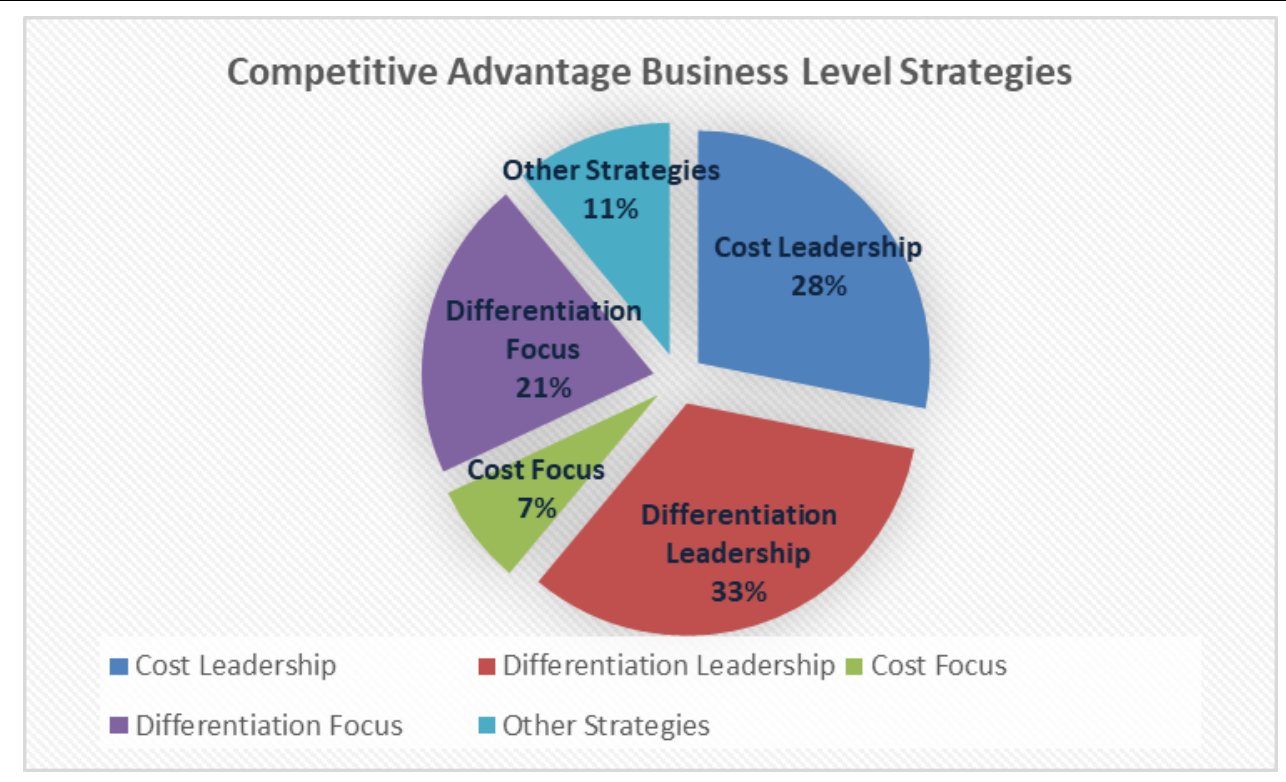

Figure 4: Competitive Advantage Business-level strategies

It's very noticeable that the micro organizations have the highest counts in all strategies. The big organizations have the highest percentages when it comes to the "other" strategies, which were not mentioned as an answer option in the survey. However, the majority of organizations are applying product/service differentiation strategy. They offer a product or service that is in high demand, but with unique characteristics. On the other hand, the minority of organizations focus on the cost (7\%). They offer a product or service in a niche market, and they ensure the lowest possible price.

Out of the 33\% applying differentiation, $9 \%$ are in the sector "Other Services", which is the highest score for this strategy option. Out of the 28\% using cost leadership, $7 \%$ are in to category "Other Services" and another 7\% in the category "Wholesale \& Retail". Out of the 21\% using differentiation focus, $8 \%$ are in sector "Other Services".

The following can be concluded regarding the business level strategies related to size: $33 \%$ of organizations use the differentiation strategy, whereas $29 \%$ belong to the micro organization and $25.5 \%$ belong to the big category; $28.2 \%$ organizations use the cost leadership strategy and most of them are the micro organizations.

Organizations older than 21 years use the differentiation strategy the most and next the cost leadership strategy.

\section{DISCUSSION, CONCLUSIONS AND RECOMMENDATIONS}

The results of this study were analyzed and discussed. This has led to a few overall conclusions that are solely based on and limited to the survey.

The bigger organizations are usually older than 21 years. It is also evident that the older the organization, the greater the chance that they have a strategic plan in place. These older organizations ascribe more value to a strategic plan compared to the younger and less mature organizations. This conclusion is consistent with the findings of Mintzberg (1979), the icon of the contingency theory, who states, "The older the organization, the more elaborate its structures." Along this line of reasoning one might state: the older the organization, the more formalized its process of developing the strategy. 
There is some indication that the political, legal and economic factors are interrelated. In the past four years in Suriname the political environment has been very unstable and as a result the economy has been shaky as well. This led to numerous strategy changes for organizations.

The Surinamese organizations are aware that the business strategy must be aligned with the social factor of the PESTLE method. This factor considers the social environment of the market and determinants like cultural trends, population analytics, etc., which are very important in Suriname, with the different population groups and associated cultures, for doing business.

Five of the six PESTLE factors are considered to be very important to the strategies of the surveyed organizations. One, the ecology factor, is deemed to be of lesser importance to sectors other than agricultural and mining.

When asked to specify which option best describes their strategy, a large number of organizations stated differentiation.

Does size of the organization determine whether or not strategic planning is being used by management?

The size of the organization does have some influence on whether or not they have a strategic plan. The size does matter, because $58 \%$ of the organizations that have a strategy contain at least 50 personnel and more. The size of the organization is relevant to the strategy. Most of the big and middle organizations do have a written strategic plan, while only $61 \%$ of the small and $36 \%$ of the micro organizations have a written strategic plan.

Does the age of the organization influence the strategy?

With reference to the analysis we can conclude that the age of the organization does have an influence. Most respondents from an organization with a higher age say that they have a strategy plan that is $45.5 \%$.

We also see that $63.9 \%$ of the organizations do have a written strategic plan. The organizations that do have a written plan are older, $44.7 \%$ of the total population. The younger the organization, the lower the percentage of the organization with a strategic plan.

We also conclude that the organizations which are younger than five years are more international oriented, followed by organizations between 6 and 10 years old. The organizations reflect the era of globalization in which they were established.

Does category of the organization determine if management is using strategic planning? There is no definite answer. The sector that has the highest percentage of having a written strategic plan that is internationally oriented is the sector "Other Services", and the lowest percentages are in the sector "Hospitality, Food \& Beverage".

To what extent do macro environmental factors influence the strategy of a business? Eightyone percent of the organizations find that the economy has an important influence on their strategies.

If we consider the six factors-politics, economy, social context, technology, legal framework and ecology - we can conclude (according to the results) that economy is the most influential factor according to all the respondents (if we look at the different sizes of the organizations), 
followed by technology and legal framework. Micro sized organizations are the organizations that deal with these factors the most.

How many organizations per category are applying Competitive Advantage Business-level strategy option? Of the respondents who have a written strategic plan: $30 \%$ has a differentiation strategy, $18 \%$ have a differentiation focus strategy, $6 \%$ have a cost focus strategy and $23 \%$ have a cost leadership strategy. It is recommended that micro and small organizations write their strategic plan. Most other organizations have a strategy plan, but not in writing. Further, organizations should consider the technology factors that have great influence on the strategy of the organization. More organizations should be internationally oriented and plan ahead, and every organization should have a mission and a vision statement. Sustainable development should be high on the agenda of the organization.

The findings of this research are limited, primarily because the survey is based on a convenience sample. Therefore, generalization of the findings is not possible. Also, because it regards the case of Suriname, it is not compared to other SIDS or other countries. Nonetheless, it is an interesting first step for further research on strategy development by organizations in Caribbean SIDS. We recommend the following:

A comparative study between countries like Suriname, British Guyana, French Guyana, Trinidad and Curaçao might provide more insight into this matter of strategizing by organizations in Caribbean Small Island Developing States.

We recommend further research to find out what specific influence the PESTLE factors have on the organization strategy.

We recommend further research to find out why some PESTLE factors are more important than others.

Awareness for the ecological factor is increasing. That is why we recommend more attention to increase awareness for this factor. The government can raise awareness by implementing awareness programs, legislation and regulation.

\section{References}

Bughin, J., Corb, L., Manyika, J., Nottebohm, O., Chui, M., de Muller Barbat, B., \& Said, R. (2011). The impact of Internet technologies: Search. McKinsey \& Company.

Cadle, J., Paul, D., \& Turner, P. (2010). Business analysis techniques: 72 essential tools for success. BCS, The Chartered Institute.

Castaño, M. S., Méndez, M. T., \& Galindo, M. Á. (2015). The effect of social, cultural, and economic factors on entrepreneurship. Journal of Business Research, 68(7), 1496-1500.

Contributor, P. (2018, March 27). Political factors affecting business. Retrieved from http://pestleanalysis.com: http://pestleanalysis.com/political-factorsaffecting-business/ NIMOS. (2018, march 26). www.nimos.org. Retrieved from http://www.nimos.org/smartcms/default.asp

Derlagen, C., Tas, J., Boyce, R., Shik, O., \& De Salvo, C. P. (2017). Analysis of agricultural policies in Suriname. IDB Monograph (Climate Change and Sustainable Development Sector. Environment, Rural Development and Disaster Risk Management Division); IDB-MG-540.

Hout, W. (2014). 'Confidence in our own Abilities': Suriname's state oil company as a pocket of effectiveness.

MacDonald, S. (2018). Suriname’s economic crisis. Retrieved from https://www.csis.org/analysis/surinameseconomic-crisis

Mintzberg, H. (1979). The structuring of organizations. Englewood Cliffs, NJ: Prentice Hall.

Mintzberg, H., Ahlstrand, B., \& Lampel, J. (1998). Strategy safari. 
Oxford. (2018, march 29). Oxford College of Marketing. Retrieved from

https://blog.oxfordcollegeofmarketing.com/2 016/06/30/PESTLE-analysis/

Peters, A. (2017). Estimating the size of the informal economy in Caribbean States. Inter-American Development Bank.

Porter, M. E. (2018, March 29). Harvard Business Review. Retrieved from https://hbr.org/1996/11/what-isstrategy

Thornton, P. H.-S. (2011). Socio-cultural factors and entrepreneurial activity: An overview. International Small Business Journal, 29(2), 105-118.

What is Strategy? / tutor2u Business. (2018). tutor2u. Retrieved 9 May 2018, from

https://www.tutor2u.net/business/reference/what-is-strategy

Roseval, W. R. (1995). Crisis and success in Surinam: An inquiry into small farms and (craft-based) small and medium industries. Crisis and success in Surinam: an inquiry into small farms and (craft-based) small and medium industries.

Schmeitz, M. (2018). Want in a rich country / Social Watch. [online] Socialwatch.org. Available at: http://www.socialwatch.org/node/10887 [Accessed 15 May 2018].

Yüksel, İ. (2012). Developing a multi-criteria decision making model for PESTLE analysis. International Journal of Business and Management, 7(24), 52. 